\title{
AC 2007-3128: IMPLEMENTING A NEW APPROACH TO TEACHING THE ETHICS OF EMERGING TECHNOLOGY
}

Doug Tougaw, Valparaiso University

Michael McCuddy, Valparaiso University 


\title{
IMPLEMENTING A NEW APPROACH TO TEACHING THE ETHICS OF EMERGING TECHNOLOGY
}

\author{
Douglas Tougaw ${ }^{1}$ and Michael K. McCuddy ${ }^{2}$ \\ ${ }^{1}$ Valparaiso University, Valparaiso, IN; Email: Doug.Tougaw@valpo.edu \\ ${ }^{2}$ Valparaiso University, Valparaiso, IN; Email: Mike.McCuddy@valpo.edu
}

\section{INTRODUCTION}

Emerging technology holds great promise for solving many of the problems facing the modern world and for improving the lives of every person in that world. However, it also holds great peril for creating new problems and for destroying the world as we know it. Engineers are in a unique position to understand the technical issues surrounding the emerging technology they are helping to create, and it is imperative that we, as engineering educators, help them to develop the knowledge, skills, and attitudes to help society make wise choices concerning the development and application of emerging technologies. We must help them to recognize the larger societal context of their work in order to ensure that they will use their engineering skills to improve the world, rather than to destroy it (Davis, 1999; Gorman and Mehalik, 1997; Kline, 2001; Nichols, 1999; Soudek, 1999; Stephan, 1999).

The American Society for Engineering Education (ASEE) has gone so far as to say that, "to survive in the work world of the 21 st century and to carry out responsibly their roles as agents of technological change, new engineering graduates need substantial training in recognizing and solving ethical problems"(http://www.asee.org). All of these emerging issues of engineering ethics have prompted the Accreditation Board for Engineering and Technology (ABET) to specifically identify "an understanding of professional and ethical responsibility" and "the broad education necessary to understand the impact of engineering solutions in a global and societal context" as two of only eleven specifically enumerated criteria that all engineering graduates must possess (Herkert, 1999; Pfatteicher, 1999).

In previous work, the authors have presented a proposed teaching method by which students' common childhood experiences can be used as an important tool in promoting understanding of the complex issues associated with the ethics of emerging technology (McCuddy and Tougaw, 2005a; McCuddy and Tougaw, 2005b; Tougaw and McCuddy, 2005). In this paper, we will describe the use of this teaching method in demonstrating how three different aspects of human development can effectively illustrate a variety of issues associated with emerging technologies.

\section{CULTIVATING AN UNDERSTANDING OF THE ETHICS OF EMERGING TECHNOLOGY}

Many different models and approaches have been used to teach engineering students about the ethics of emerging technology. Entire textbooks have been dedicated to the specific task of teaching the topic of "engineering ethics," which includes not only the issues surrounding emerging technology, but also issues of professionalism and safety (Johnson, 1991; Martin and Schinzinger, 1996; Petroski, 1982; Taylor, 1975; Gunn and Vesilund, 2002, among many others). In addition to 
these resources, several national organizations have published resources designed to help engineering educators impart ethical concepts to their students (Elbaz, 1990; Wujek and Johnson, 1992).

A great deal of early work in this area focused on ethics as an exclusively moral issue (Goldman, 1979; Whitbeck, 1995), while recent work has also considered ethics as a component of professionalism, risk management, and legal liability (Firmage, 1980; Flores, 1988; Schaub and Pavlovic, 1983; Vaughn, 1977). With an increasing emphasis by modern society on sustainable design, engineering ethics is also being tied irrevocably to environmental issues (Gunn and Vesilund, 1986). The emergence of massively powerful computer technology over the past thirty years has also led to a detailed study of the application of engineering ethics to computers and digital communication technology (Johnson and Snapper, 1985; Unger, 1982). Much of this work makes heavy use of case studies to demonstrate the issues of engineering ethics to students, helping them learn from the successes and failures of the past.

While each of these approaches to teaching ethics to engineering students has significant benefits, they are very frequently focused on relatively personal issues such as bribery and whistle blowing. While these issues are important, and it is essential that we convey this information to our students, such approaches do not focus on the larger, society-changing effects of emerging technology. Such issues are frequently difficult to discuss, since they are very complex. Also, by its very nature, emerging technology is unpredictable. Case studies may not be the most effective way to teach students about emerging technology, since the new technology may be completely different than anything previously developed. What is needed is a method to instill in the students a set of principles that they can use to make decisions about previously unimagined technological developments.

\section{HUMAN DEVELOPMENT AND EMERGING TECHNOLOGY}

How, then, does one convey the ethical issues associated with emerging technology to undergraduate engineering students? It seems logical that the most effective way to do so is to build directly on the students' own personal life experiences. Upon careful review, it is just possible that our students have all had exactly the sort of experience that can help them to see how developments bring with them moral obligations. Every student in every engineering classroom in the country has shared some very common experiences, and we can use those experiences to help them see that society has always assigned power and responsibility in equal measures. By presenting students first with the story of an infant growing successfully to adulthood, followed by a discussion of societies developing from hunter-gatherers to modern, power countries, we can help students to see how their personal actions as engineers must be made in the context of the effects of those actions on others. When one studies the development of an individual human being from infancy to adulthood, several key patterns can be observed. It is possible to use three of these developmental patterns to help students learn important lessons about the ethics of emerging technology.

\subsection{Increasing power is accompanied by increasing responsibility.}

Human development is accompanied by continually increasing control over one's environment. Whether this is the ability to walk, to talk, or to drive a car, growth from infancy to adulthood is a story of increasing ability and power. With each of these increases in power, though, comes new 
responsibility to use that power wisely, benefiting not only the individual but also society. No sooner does a child learn to talk than he or she is taught not to lie. The ability to walk is closely followed by an understanding of how to cross the street safely, and of course the ability to drive a car is balanced by a need to demonstrate an understanding and acceptance of the laws accompanying that ability.

In the same way, students can be shown that every development in technology should be accompanied by new responsibilities. This is obvious in some cases such as the dedication to safety that must accompany the development of a nuclear power plant. However, other examples can be even more rewarding for students. For instance, many students struggle to think of ethical implications of the ancient developments of pottery and the plow. However, both of these developments were accompanied by new ideas-in the case of pottery, the idea of personal property and the obligation to share stored food with others in times of famine; while in the case of the plow, the idea that a person can "own" land and can be guaranteed of the right to reap the benefits of work done to improve that land.

Perhaps even more useful are the numerous examples of technologies that were not appropriately accompanied by responsibilities, leading to repulsive historical results. For example, compasses and cartography enabled the development of very beneficial maritime trade, but these same technologies also enabled the development of the slave trade. Similarly, the development of the internal combustion engine has revolutionized the world in the last century, but its unchecked development is likely to lead to severe environmental repercussions in the next century. Many other examples can be used to demonstrate the horrific repercussions of developing new technologies without the accompanying wisdom and self-restraint necessary to use those new developments in the best interest of all involved.

\subsection{Delaying gratification leads to the accomplishment of important long-term goals.}

A very young child is largely incapable of delaying gratification without parental intervention. Young children strive to have every wish satisfied immediately, if possible. Through steady and wise parental guidance, children slowly develop an understanding that they can achieve much greater happiness if they are willing to defer their instant gratification in exchange for the accomplishment of long-term goals. College students, in particular, can see this clearly, because they are in the midst of a four-year goal to achieve a long-term objective that will dramatically improve the quality of the rest of their lives.

Similarly, such an understanding can help students to see that society can achieve much greater goals if the people and their leaders are willing to sacrifice short-term pleasure in order to achieve long-term goals. Many examples of great technological achievements can be used to demonstrate this point. From the building of Roman architectural marvels to the construction of the interstate highway system, the history of technology is largely the history of deferred gratification.

This lesson is also important to help the students see that seemingly insurmountable problems can be solved if those involved are committed to a long-term view of solving the problem. Just as a child develops very slowly over a period of many years, with imperceptible changes day by day, so problems such as global warming and the erosion of the ozone layer can be solved with a vision to making small, almost imperceptible changes over a period of many years. Just as it would be 
completely inappropriate to tell a child to grow up overnight, so it is inappropriate to attempt to solve critical global issues overnight. These problems were not caused overnight, and their solution will likely take at least as long as the conditions that caused them.

\subsection{Building relationships carries with it responsibility to protect privacy.}

As a child grows up, he or she will develop many personal relationships. Some of these, such as with parents and siblings, will be extremely close and important to the survival of the child. Others, such as school friends and extended family, will provide important information and other resources to the child. Still others will be merely acquaintances. It is natural that those closest to the child will know the most private information about him or her, and vice versa. The child probably knows very intimate details of his/her parents' lives, but little or nothing about the private life of casual friends.

Building these relationships has many advantages for the child, and sharing personal information is one way of strengthening those relationships. Whether it is a five-year-old telling a secret to a friend or a teenager discussing a life-changing decision with a parent, relationships are built on the mutual sharing of information and judgment. However, one of the impediments to the development of these relationships in very young children is an inability to maintain the confidentiality of this information. A young child exhibits very few ways of acting and does not recognize that some information should remain confidential. It is only after the ability to protect another's privacy develops, that stronger relationships can begin to be established outside of the immediate family.

Similarly, modern business organizations rely on the acquisition and use of confidential personal information about their customers in order to succeed. Whether this information consists of credit card numbers, medical history, or purchasing records, it is essential to the operation of the business and is considered to be highly personal and confidential to the customer. The students can help to see that the growth of digital communications and the Internet have brought about a revolution in the acquisition and application of information, but that it also brings with it a high risk for the misuse of that information. When a customer shares her credit card number with a company, she places a trust in the company to use that information only as they have previously agreed to be appropriate. Other uses or carelessness with the information will lead to a degradation of the relationship with the customer, to the company's disadvantage.

\subsection{Intellectual Power and Ethical Obligations}

The nature, complexity, and impact of the moral issues associated with the different stages of these three aspects of human development help to identify and illuminate important ethical parallels in the emergence of various technologies throughout the existence of humankind. The foundational attitude that must be conveyed to engineering students is that their intellectual power carries with it very real ethical and moral obligations. This is a modern application of the concept of noblesse oblige, a medieval belief that the wealthy and privileged are obliged to help those less fortunate. Literally translated, it means "nobility obligates." In the seventeenth century, this meant that those with financial resources and noble titles were obligated to help those in lower social positions. A useful way of conceptualizing today's nobility is that it consists of those with the intellect and education to understand and develop state-of-the-art engineering designs, and they are obligated to help the rest of society every bit as much as a French nobleman was three hundred years ago. It is our responsibility to help students recognize and accept this responsibility. 


\section{EXPERIMENTAL METHODOLOGY}

From an instructional viewpoint, this framework for cultivating an understanding of the ethics of emerging technology leads to three broad but definitive learning objectives (McCuddy and Tougaw, 2005a). Specifically, students should recognize that: (1) "Technological advancements create power over the physical and social environments, and this power is accompanied by the responsibility to use it wisely." (2) "Technological advancements create vast databases of highly confidential personal information, and this information is accompanied by the responsibility to protect it diligently." (3) "Technological advancements create obligations to focus on longer-term societal goals and to defer immediate gratification in the interests of achieving sustainability."

In order to achieve these learning objectives, the authors have developed and implemented a fourstep teaching process. In the first step, the instructor describes key developmental stages for human beings and the ethical issues encountered at these different stages. The instructor highlights appropriate life events with which the students can easily identify and that support the learning objectives. In the second step, the instructor guides the students in identifying the fundamental lessons that can be derived from examining the process of human development. In the third step, the instructor helps the students to understand that these fundamental life lessons have analogues in the ethical challenges encountered by society with regard to emerging technologies, and that these challenges have unfolded and grown over the course of human history. In the fourth step, the students identify and discuss the ethical implications of important technological developments throughout history. This four-step sequence is illustrated in Figure 1.

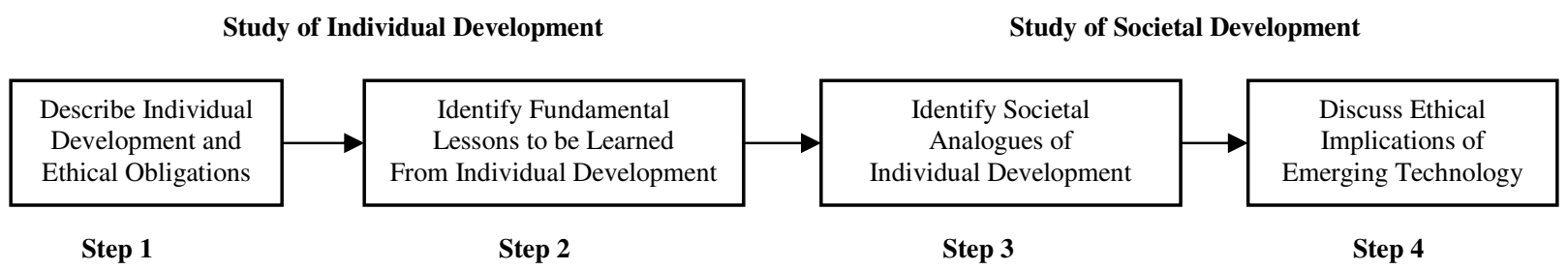

Figure 1. The four-step teaching sequence

The authors have used this teaching method in leading two class sessions of four different course sections of both engineering and business students. At the beginning of the first class session, students completed a 17-item questionnaire that measured knowledge, attitudes, and behaviors that hopefully would be influenced by the training sessions. During the two training sessions, the presentation and discussion reflected the material in section 3 of this paper. At the end of the second class session, the students completed the 17-item questionnaire again; the questions, however, were presented in a different order than in the first administration of the survey. The pretest/posttest administration of the questionnaire enabled us to ascertain if any change could be attributed to the impact of the presentations, thereby demonstrating the effectiveness of this pedagogical technique

The questionnaire items focused on (1) the interconnection of ethics and technology and (2) the ethical implications of the fundamental lessons derived from our approach. Table 1 contains the questions, organized according to the predetermined knowledge, attitudes, and behavioral change categories. The response scale was as follows: $1=$ strongly disagree, $2=$ moderately disagree, $3=$ 
slightly disagree, $4=$ neither disagree not agree, $5=$ slightly agree, $6=$ moderately agree, and $7=$ strongly agree.

\section{EXPERIMENTAL RESULTS}

Initial analysis of the data focused on ascertaining whether or not the 17 questions empirically clustered as expected based on the conceptual construction of the questionnaire (see Table 1). Cronbach's coefficient alpha, a measure of internal consistency reliability, was .475 for the 6 -item

\begin{tabular}{|c|c|}
\hline \multicolumn{2}{|r|}{$\begin{array}{c}\text { Table } 1 \\
\text { Pretest/Posttest Questions (Arranged According to Predetermined Conceptual categories) }\end{array}$} \\
\hline Questions & Items Intended to Measure KNOWLEDGE CHANGES \\
\hline Q1 & $\begin{array}{l}\text { I believe that the process of human maturation and the ethical implications of emerging } \\
\text { technologies are interconnected phenomena. }\end{array}$ \\
\hline Q2 & I believe that interconnections potentially exist among all worldly phenomena. \\
\hline Q3 & $\begin{array}{l}\text { In practicing my chosen profession, it is important for me to go beyond the knowledge } \\
\text { provided by my own major to find solutions for the problems and challenges encountered in } \\
\text { contemporary society. }\end{array}$ \\
\hline Q4 & $\begin{array}{l}\text { I believe that technological developments have few, if any, potential ethical implications. } \\
\text { (reverse scored) }\end{array}$ \\
\hline Q5 & $\begin{array}{l}\text { I believe that ethical implications do not need to be addressed in designing and using } \\
\text { technologies. (reverse scored) }\end{array}$ \\
\hline \multirow[t]{2}{*}{ Q6 } & $\begin{array}{l}\text { I believe that the ethical implications of technological developments are extremely complex } \\
\text { and far-reaching. }\end{array}$ \\
\hline & Items Intended to Measure ATTITUDIAL CHANGES \\
\hline Q7 & $\begin{array}{l}\text { I feel overwhelmed by the massive nature of some of the challenges posed by emerging } \\
\text { technologies. (reverse scored) }\end{array}$ \\
\hline Q8 & $\begin{array}{l}\text { I believe that directly confronting the moral challenges of technological advancements } \\
\text { better enables technology to serve humankind. }\end{array}$ \\
\hline Q9 & $\begin{array}{l}\text { I am fearful of the prospect that emerging technologies are transforming the realm of } \\
\text { science fiction into the world of reality. (reverse scored) }\end{array}$ \\
\hline Q10 & $\begin{array}{l}\text { I believe that directly confronting the moral issues associated with emerging technologies } \\
\text { should help alleviate any anxiety I have regarding the development and use of these } \\
\text { technologies. }\end{array}$ \\
\hline \multirow[t]{2}{*}{ Q11 } & I believe that ethics is a very important part of my chosen profession. \\
\hline & Items Intended to Measure BEHAVIORAL CHANGES \\
\hline Q12 & $\begin{array}{l}\text { I believe that true competency in my chosen profession incorporates ethical thinking into all } \\
\text { decisions and actions. }\end{array}$ \\
\hline Q13 & $\begin{array}{l}\text { I believe that ethical issues should be addressed only when forced to do so by external } \\
\text { parties. (reverse scored) }\end{array}$ \\
\hline Q14 & $\begin{array}{l}\text { I believe that ethical issues should be addressed only when there are adequate resources to } \\
\text { do so. (reverse scored) }\end{array}$ \\
\hline Q15 & $\begin{array}{l}\text { I believe that I should consider the moral implications of my use of technology in my } \\
\text { personal life. }\end{array}$ \\
\hline Q16 & $\begin{array}{l}\text { I believe that I should consider the moral implications of my use of technology in my } \\
\text { chosen professional life. }\end{array}$ \\
\hline Q17 & $\begin{array}{l}\text { I am able to use theories, models, concepts, and ideas from one knowledge domain to help } \\
\text { inform and guide my work in another knowledge domain. }\end{array}$ \\
\hline
\end{tabular}

knowledge change scale, .351 for the 5-item attitude change scale, and .697 for the 6-item behavioral change scale. Consequently, we decided that insufficient justification existed for 
aggregating the questions into the predetermined knowledge, attitude, and behavioral change scales; instead, we did separate analyses of the responses to each of the 17 questions.

Additional preliminary analysis of the data focused on a comparison of pretest scores between the engineering and ethics students to determine whether the groups differed on the dependent measures prior to the ethics of emerging technologies training program. An independent samples $t$ test of the equality of means for the engineering students versus the ethics students revealed a significant difference in the pretest scores for the two groups on Q1 but not on any of the other questions. The mean for engineering students was .83 higher than the mean for the ethics students (5.77 vs. 4.94), indicating a stronger pretest belief in the connection between human maturation processes and emerging technologies. Perhaps this is understandable given that the profession of engineering is about technology.

The responses to each of the 17 questions were analyzed with the General Linear Models Repeated Measures module of SPSS13.0. This produced 17 repeated measures univariate analyses of variance (ANOVAs) where the single between-subjects factor was the course (engineering vs. ethics), and the two within-subjects factors were the training impact (pretest measurement vs. posttest measurement) and the training $\mathrm{x}$ course interaction. The results of this analysis are presented in Table 2, and significant differences at $\mathrm{p} \leq .10$ are shown in the shaded boxes. While using the .10 significance level is common in exploratory research like the present study, it should be noted that all but two of the significance differences also meet the more rigorous $\mathrm{p} \leq .05$ level.

\begin{tabular}{|c|c|c|c|c|c|c|}
\hline \multicolumn{7}{|c|}{$\begin{array}{c}\text { Table } 2 \\
\text { Repeated Measures ANOVA Results }\end{array}$} \\
\hline \multirow{3}{*}{$\begin{array}{c}\text { Survey } \\
\text { Questions }\end{array}$} & \multicolumn{2}{|c|}{ Between-Subjects Effects } & \multicolumn{4}{|c|}{ Within-Subjects Effects } \\
\hline & \multicolumn{2}{|c|}{ Course } & \multicolumn{2}{|c|}{ Training } & \multicolumn{2}{|c|}{ Training x Course } \\
\hline & $\mathbf{F}$ & Sig. & $\mathbf{F}$ & Sig. & $\mathbf{F}$ & Sig. \\
\hline $\mathrm{Q} 1$ & 13.875 & .000 & 11.874 & .001 & .981 & .326 \\
\hline $\mathrm{Q} 2$ & .000 & .994 & 22.796 & .000 & .502 & .481 \\
\hline Q3 & .000 & .987 & .771 & .383 & .023 & .880 \\
\hline $\mathrm{Q} 4$ & .046 & .832 & 2.504 & .119 & .001 & .973 \\
\hline $\mathrm{Q} 5$ & .732 & .395 & .355 & .553 & .173 & .679 \\
\hline Q6 & .233 & .631 & 3.493 & .066 & 1.422 & .238 \\
\hline Q7 & .609 & .438 & .355 & .553 & .173 & .679 \\
\hline $\mathrm{Q} 8$ & 1.227 & .272 & 21.362 & .000 & 1.408 & .240 \\
\hline Q9 & .053 & .818 & 8.525 & .005 & 1.842 & .180 \\
\hline Q10 & .955 & .332 & 1.742 & .192 & .734 & .395 \\
\hline Q11 & .554 & .460 & .610 & .438 & 2.229 & .141 \\
\hline Q12 & .035 & .853 & 10.563 & .002 & .001 & .977 \\
\hline Q13 & 4.576 & .036 & .664 & .418 & .020 & .888 \\
\hline Q14 & .013 & .908 & .302 & .584 & .302 & .584 \\
\hline Q15 & 1.532 & .220 & 13.767 & .000 & .248 & .620 \\
\hline Q16 & .000 & .993 & 11.979 & .001 & .084 & .773 \\
\hline Q17 & .033 & .857 & 3.232 & .077 & .125 & .725 \\
\hline & & & & & & \\
\hline
\end{tabular}

As shown in Table 2, no significant training $x$ course interaction existed for any of the questions. A main effect reflecting differences between the engineering students and the ethics students was found for $\mathrm{Q} 1(\mathrm{M}=5.984$ and $\mathrm{M}=5.318$ for engineering and ethics, respectively) and $\mathrm{Q} 13(\mathrm{M}=$ 
6.355 and $\mathrm{M}=5.924$ for engineering and ethics, respectively). The engineering students had a stronger perception of the connection between the human maturation process and the ethics of emerging technologies and they believed more strongly that ethical issues must be addressed even when not forced to do so by external parties.

In terms of assessing ethics training efficacy, a significant training main effect was found on nine of the 17 questions. Table 3 presents the marginal means for all questions with a significant training main effect. The marginal means on all but one of these nine significant main effects (i.e., Q9) reflected a pretest/posttest enhancement of the students' understanding/capability with regard to the ethical implications of emerging technologies. Interestingly, the results for Q9 were the exact opposite of what had been anticipated - pretest scores were higher than posttest scores, indicating lesser level of fear of emerging technologies before the training than after it. Apparently, the training sessions sensitized students to technology's potential to turn science fiction into reality a reality with potentially significant unanticipated and dangerous consequences. However, the marginal means for Q9 clustered around the neutral point of the scale, which was not the case with any of the other questions in Table 3.

\begin{tabular}{|c|c|c|}
\hline \multicolumn{3}{|c|}{ Table 3 } \\
$\begin{array}{c}\text { Marginal Means for Survey Questions with a } \\
\text { Significant Training Main Effect }\end{array}$ \\
\hline \hline $\begin{array}{c}\text { Survey } \\
\text { Questions }\end{array}$ & Pretest Mean & Posttest Mean \\
\hline Q1 & 5.357 & 5.945 \\
\hline Q2 & 5.264 & 5.798 \\
\hline Q6 & 5.015 & 5.350 \\
\hline Q8 & 5.974 & 6.408 \\
\hline Q9 & 4.176 & 3.780 \\
\hline Q12 & 6.047 & 6.438 \\
\hline Q15 & 5.597 & 6.052 \\
\hline Q16 & 6.078 & 6.375 \\
\hline Q17 & 5.843 & 6.031 \\
\hline
\end{tabular}

\section{DISCUSSION OF RESULTS}

The within-subjects training effect that was found for nine of the 17 questions indicates that the ethics of emerging technologies training session produced change among the students. The findings for eight of the questions indicate that the training program produced the desired change. The results for one question (i.e., Q9) revealed an impact opposite of that which we expected. In addition, an inspection of the marginal means for the eight questions with the anticipated training effect reveals pretest/posttest differences ranging from .188 to .588 , with three of the eight being $\geq$ .335. A difference of .3 or more, on a scale ranging from 1 to 7 , is a relatively impressive feat to be accomplished over just two class sessions. Moreover, we were dealing with relatively welleducated people with respect to technology and its implications, and consequently would expect smaller changes. In contrast, we would expect to find a much greater pretest/posttest difference among groups of students with a lower level of sophistication regarding technology and it implications. On balance, reasonable evidence exists regarding the efficacy of the ethics education approach we have developed. 
The impact of the training for the engineering students may have been mitigated — ironically — by technology. The PowerPoint projection system in the classroom in which the engineering students met was less than fully functional given poor in-room lighting. Thus, the engineering students did not have the same level of clear exposure to the PowerPoint slides as the business students did. Had the engineering students enjoyed the same level of exposure, we might have seen even more dramatic results.

\section{CONCLUSIONS}

The results of our experiment are encouraging, providing evidence that the human development metaphor is a viable approach for educating people regarding the ethical implications of technology. This approach can be applied to understanding the history of society's technological developments and the increasingly complex and profound moral challenges that accompanied those developments. This approach can also be used to foster an enriched understanding of the ethical implications of the technologies that are emerging now and those that will emerge in the future.

We believe this educational approach holds considerable promise. The results reported herein reflect an initial exploratory study; clearly, future research is warranted to more fully ascertain the general utility and applicability of our approach. Additionally, the training program represented the first iteration of teaching ethics of technology concepts using the human development metaphor. As with any first iteration, there are areas that can be refined and improved. Subsequent iterations can fine-tune the training to be even more impactful.

A final observation is worth noting. Our experiment shows that complex concepts, such as the interplay of technology and ethics, can be effectively explored in short training programs. Such programs can have an appreciable impact, even with well-educated people.

In conclusion, technology and ethics are intertwined phenomena with increasingly complex and profound implications for humanity. All the inhabitants of this planet are increasingly impacted by the moral consequences of emerging technologies. Having the capability to better understand and deal with those moral challenges will benefit everyone - and we believe our approach can be a very fruitful option in these endeavors.

\section{REFERENCES}

Davis, M. (1999), “Teaching ethics across the engineering curriculum," Proceedings of the International Conference on Ethics in Engineering and Computer Science, March 21-24, 1999, available at http://www.onlineethics.org.

Elbaz, S.W. (1990), Professional Ethics and Engineering: A Resource Guide, National Institute for Engineering Ethics, Arlington, VA.

Firmage, D.A. (1980). Modern Engineering Practice: Ethical, Professional, and Legal Aspects, Garland STPM, New York.

Flores, A. (1988). Ethics and Risk Management in Engineering, Westview Press, Boulder, CO.

Goldman, A.H. (1979). The Moral Foundations of Professional Ethics, Rowman and Littlefield, Totowa, NJ. 
Gorman, M.E. and Mehalik, M.M. (1997), "Using detailed, multimedia cases to teach engineering ethics," Proceedings of the 1997 American Society for Engineering Education Annual Conference.

Gunn, A.S., and Vesilund, P.A. (1986). Environmental Ethics for Engineers, Lewis Publishers.

Gunn, A.S., and Vesilund, P.A. (2002). Hold Paramount: The Engineer's Responsibility to Society, Thomson Engineering.

Herkert, J.R. (1999), “ABET's engineering criteria 2000 and engineering ethics: where do we go from here?," Proceedings of the International Conference on Ethics in Engineering and Computer Science, available at http://www.onlineethics.org.

Johnson, D.G. and Snapper, J.W. (1985). Ethical Issues in the Use of Computers, Wadsworth Publishing, Belmont, CA.

Johnson, D.G. (1991). Ethical Issues in Engineering, Prentice-Hall, Englewood Cliffs, NJ.

Kline, R. (2001). "Using history and sociology to teach engineering ethics," IEEE Technology and Society, 20(4), pp. 13-20.

Martin, M., and Schinzinger, R. (1996). Ethics in Engineering, 3rd ed. New York: McGraw-Hill.

McCuddy, M.K. and D. Tougaw (2005a), "Learning Challenges in Contemporary Society: Fostering Understanding of the Ethical Implications of Advancing Technologies," presented at the Educational Innovation in Economics and Business 2005 Annual Conference.

McCuddy, M.K. and D. Tougaw (2005b), “The Ethical Imperatives of Technological Development: Insights Gained by Using the Individual Human Being as an Analogy for Societies," Proceedings of the Global Conference on Business and Economics.

Nichols, S. P. (1999), "Designing engineers: integration of engineering 'professional responsibility' in the capstone design experience," Proceedings of the International Conference on Ethics in Engineering and Computer Science, March 21-24, 1999, available at http://www.onlineethics.org.

Petroski, H. (1982). To Engineer is Human: the Role of Failure in Successful Design, St. Martins Press, New York.

Pfatteicher, S. K.A. (1999), "EC2000 and the engineering ethics dilemma," Proceedings of the International Conference on Ethics in Engineering and Computer Science, March 21-24, 1999, available at http://www.onlineethics.org.

Schaub, J.H. and Pavlovic, K. (1983). Engineering Professionalism and Ethics, Wiley.

Soudek, I.(1999). "Turning belief into action: aims of teaching engineering ethics," 1999 American Society for Engineering Education Annual Conference Proceedings. Washington, DC.

Stephan, K. (1999). "A survey of ethics-related instruction in US engineering programs," Journal of Engineering Education, 88, pp. 459-464.

Taylor, P.W. (1975). Principles of Ethics, An Introduction, Dickenson, Encino, CA.

Tougaw, D. and M.K. McCuddy (2005), "Using Childhood Experiences as an Analogy to Teach Students About the Morality of Emerging Technology" Proceedings of the American Society for Engineering Education Illinois/Indiana Conference.

Unger, S.H. (1982). Controlling Technology: Ethics and the Responsible Engineer, Holt, Rinehart and Winston, New York.

Vaughn, R.C. (1977). Legal Aspects of Engineering, Kendall/Hunt Publishers.

Whitbeck, C. (1995), "Teaching ethics to scientists and engineers: moral agents and moral problems," Science and Engineering Ethics, 1, pp. 299-308.

Wujek, J., and Johnson, D. (1992). How to Be a Good Engineer. Washington, D.C.: IEEE United States Activities Board. 